\title{
American Pediatric Society Presidential Address 1994 Reflections on Research: A Call to Arms
}

\author{
ABRAHAM M. RUDOLPH \\ Department of Pediatrics and Cardiovascular Research Institute, University of California, \\ San Francisco, San Francisco, California 94143
}

Members of the Society and guests, tradition requires that the President of the Society present an address on the topic of his or her choice at the annual meeting. The title I selected last fall was "The Health Care Debate: Single Payer versus Chaos." I was, however, both optimistic and naive in the belief that health-care legislation would already have been approved by this time. So then I made the decision to discuss various aspects of the research enterprise in academia that have been of concern to me. Each of the issues I propose to raise could be the subject of lengthy discussion, but because of time limitations, I will mention them only briefly.

\section{EDUCATIONAL PROCESS: RESIDENCY TRAINING}

Our current postdoctoral education system is becoming increasingly rigid. The residency in pediatrics has been extended to 3 years. Specialty board certification has been expanded to 3 years. With 3 or 4 years of college and 4 years of medical school education, most individuals, with few exceptions, are 30 to 32 years old when they complete their specialty training. In most residency programs, apart from variable periods of elective time, the experience is remarkably uniform, usually being driven by clinical needs. Furthermore, pediatric residency programs are increasingly being controlled by the residency review committees and the American Board of Pediatrics. They establish the duration and specifics of training of each resident. However, the rationale and process for differentiating between recommendations and absolute requirements in this training process is not always clear. The Residency Review Committee sets standards for training programs, and the Board of Pediatrics states the specific competencies to be mastered by the individual. During pediatric residency training, there is little time to embark on research and little opportunity for expression of individuality. In addition, most residents, in the small amount of time they have to think, are making decisions about career choices.

Correspondence: Abraham M. Rudolph, M.D., Box 0544, HSE 1403, CVRI, Pediatric Cardiology, University of California, San Francisco, San Francisco, CA 94143-0544.

\section{FELLOWSHIP TRAINING}

My comments regarding fellowship training apply to many of the specialities but are more specifically directed to Pediatric Cardiology, because this is the area in which I have had primary involvement. Here, too, we see the controlling influence of the boards, with the board of pediatrics and the sub-boards, as well as, of course, the residency review committees, all instituting regulations. Inherent in their philosophy is the fact that they do not classify these trainees as fellows, but as residents. Here, again, both content and duration of training are dictated. In recent years, all of the sub-boards have instituted a "research requirement" of all trainees, which is satisfied by publishing a paper, or if a publication is not achieved, providing evidence of having actively participated in some project. This requirement, thankfully, is vague and ill-defined. Associated with this new regulation has been, naturally, an extension of the training requirement to 3 years.

The result of all this is that the eager beavers leaving medical school have become tired old men and women on completion of the fellowship. Furthermore, the result of forcing everybody into the same mold is:

\section{An amorphous, undifferentiated mass in which individu- ality and originality have been stifled.}

So, what should we do? Well, first, I think it is time we again recognize individual ability and preference. This does not necessarily require that the total training period be reduced, but that more flexibility be allowed. Let us acknowledge that ability to assimilate information differs. Some individuals are completely competent clinically and skillful in technical procedures by the end of 18 to 24 months, whereas others do not achieve this even after 4 to 5 years of exposure. Another issue: should we insist that every resident or fellow become fully competent in every aspect of the clinical specialty? Should we not, perhaps, begin to recognize that some may want to concentrate on specific clinical areas, such as, in cardiology, electrophysiology or interventional procedures, or perhaps even research? Some have no interest in a research career, whereas others have a major commitment to research. Those who express a research interest may be 
drawn to molecular or cellular biology, systems biology, or outcomes research. We need to tailor the training experience to the individual goals. Obviously, a certain time duration is basic for achievement of clinical skills, but, by continuing evaluation, individual performance could be determined. In this way, it would be possible to reduce the clinical training period for some individuals and permit them to pursue research interests or specialty training earlier. This would, I believe, help to overcome the stifling of individuality and originality that currently prevails.

Yes, of course this will be somewhat disruptive, particularly of residency programs, as they are currently organized. But perhaps a complete review and overhaul is indicated, to permit greater individual expression.

What about the role of the boards? I do not believe that the boards should inject themselves into research issues. The board was originally established to certify clinical competence. This, I feel, is what they should do. I do not think they should direct the specifics of how individuals be trained and for how long. They should set up appropriate and reliable testing procedures that determine qualifications for clinical competence.

In addition, we should work toward exposing our residents to research and researchers in a more organized manner than is current practice in most programs. We should also orient education at an earlier stage toward future interests. For example, those who plan careers in outcome research should receive intensive training in epidemiology, whereas others should be trained in molecular or physiological or biochemical processes.

Our current policies are generally geared to assuring that everybody gains a certain body of knowledge. It is interesting that, at a time when the Japanese are becoming increasingly concerned about the rigidity and conformity of their educational system, we are moving toward uniformity in postdoctoral experience. Perhaps we should take note of Albert Einstein's philosophy:

Imagination is more important than knowledge.

\section{GRANT REVIEW MECHANISMS}

The major support for biomedical research currently is provided by the National Institutes of Health. The application for research grants has become increasingly standardized and rigid. Conformity is the order of the day. Young people are at a tremendous disadvantage, because the catchwords for success in priority scoring are research experience and productivity. The other important word is originality, which is defined in the dictionary as initiation of new ideas. However, we do appreciate that, in most instances, creativity is based on what has happened in the past. Another definition is:

Originality is the art of concealing your source (1).

The peer review mechanism is the core of the National Institutes of Health process for supporting research and research training. It is almost sacrilegious to question this process, but I wonder whether it may need review and modification. Two to three years ago, a panel assessed National Institutes of Health peer review. Their report stated that "the system had worked well over the years, and its vital role should be retained." The report addressed issues relating to membership of review committees, details of the scoring process, and such. No mention was made in the report regarding questions I have heard from a number of my colleagues regarding peer review.

An important concern is the familiarity of the reviewers with the specifics of the research proposed. Is it more favorable when reviewers are barely acquainted with the research, because they are not aware of potential problems? Is it less favorable when reviewers are actively involved in the same area of research and can thus become unduly critical of minor issues? Usually only one or two of the reviewers are fully familiar with the field of research and, especially if vocal, have a major influence on the scoring process. Also, is a reviewer who is actively engaged in a research problem in a position to be completely impartial in reviewing a proposal on similar work?

Another current concern is the role of discipline in driving research decisions. It has been stated that in some review groups, and even in some institutes, the likelihood of a proposal being awarded a fundable priority score is significantly increased if molecular and/or cellular techniques are primarily proposed, or as some have said, "if you are not cloning genes, forget it." More about this later.

I do not have specific suggestions for alternatives to the peer-review process. I do think, however, that we should not accept the status quo. I am sure that methods can be developed to examine some of the issues I have raised. This will not be easy, however, because the whole review process has become institutionalized, and it is exceedingly difficult to introduce cultural change.

\section{MOLECULAR AND SYSTEMS BIOLOGY}

I am increasingly concerned about the decline in systems, or what has been called integrated, research, at the expense of molecular and cellular disciplines. I want to make it clear that I am not expressing opposition to the current partiality toward support for molecular/cellular versus systems research; what I object to is the magnitude of the partiality. I recall when cardiac catheterization was first introduced; merely applying the procedure was considered research. Currently, a great deal of molecular biology is still in the stage of cataloguing, or as John Maddox expresses it, botanizing. His remarks concerning molecular biology, in an editorial in Nature, appropriately address the issue:

\section{... the published literature gives the impression that the authors are more concerned with the correctness of their observations than with their significance (2).}

I would like to plead for diversity. Let us not neglect training and support for systems research while pursuing 
molecular and cellular research. Although these reductionist approaches are exciting, many researchers in the molecular/cellular field are beginning to recognize the need for whole-animal models to examine the functional importance of their findings. I would like to propose that the term "integrative" biology or physiology, rather than referring to organ systems alone, as is done now, be used as a term to bring together molecular/cellular and systems research.

I would like to present an example, based on research currently in progress in my laboratory. For many years I have been interested in how the fetus responds to hypoxia. We have shown that the carotid chemoreceptor is very important in this response. The mechanisms by which the glomus cell is stimulated by hypoxia and neurotransmission of the impulse requires study at the molecular/cellular level, but resolution of these mechanisms will not explain what the results of this stimulation on various organ systems may be, nor why these effects are induced. Chemoreceptor activity is very important in determining catecholamine response. As you can see in Figure 1, hypoxemia increases plasma catecholamine concentrations in fetal lambs. When $\mathrm{Po}_{2}$ is reduced below about 15 torr, the rise in catecholamine levels is greatly diminished if chemoreceptor function is abolished.

The next question is: Why are catecholamines important? My suggestion is that their importance in the hypoxic response is related to their effect in inducing peripheral vasoconstriction (3). This results in a reduction of blood flow and $\mathrm{VO}_{2}$ in tissues that are not important for survival. Hypoxemia causes a decrease in peripheral blood flow and, as shown in Figure 2, a fall in oxygen delivery and oxygen consumption. With phentolamine (Regitine), an $\alpha$-adrenergic receptor blocker, blood flow

\section{Increase in Plasma Catecholamine Concentration During Hypoxia}

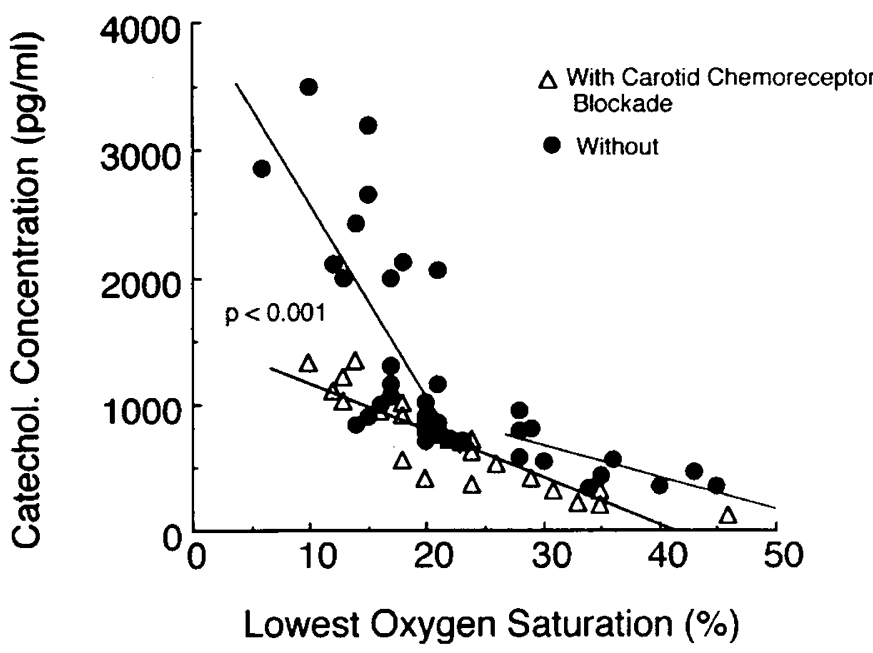

Figure 1. Plasma catecholamine concentrations are shown after induction of acute hypoxemia in fetal lambs to produce varying levels of oxygen saturation. Data are shown before and after inducing carotid chemoreceptor blockade. During blockade, the peak concentrations reached at lower oxygen saturations are markedly reduced.

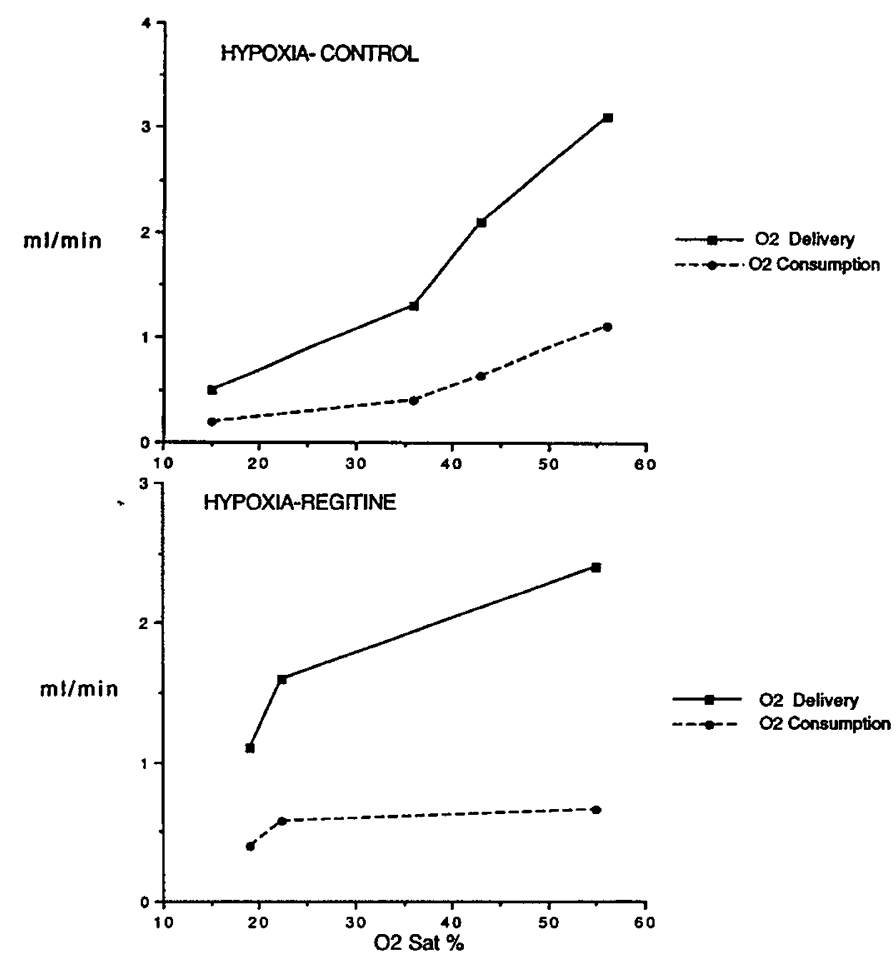

Figure 2. Effects of hypoxia of varying degree on oxygen delivery and oxygen consumption in the hindlimb of a fetal lamb with and without local infusion of phentolamine (Regitine), an $\alpha$-adrenoreceptor blocker. In the absence of Regitine, a progressive fall in oxygen delivery and oxygen consumption occurs as arterial oxygen saturation falls, associated with a fall in blood flow. During Regitine administration, oxygen consumption is maintained until very low arterial oxygen saturation levels are achieved.

does not fall, and oxygen delivery and oxygen consumption are sustained until extreme degrees of hypoxia occur. So, the interpretation of these findings is that chemoreceptor function is important for fetal survival, based on its affect on catecholamine secretion, which influences peripheral oxygen utilization, thus conserving it for vital functions. This conclusion cannot be derived by a study of cellular and molecular mechanisms alone.

Other areas for molecular/cellular exploration would be the mechanisms for catecholamine release and mechanisms by which they induce peripheral vasoconstriction.

It is not likely, considering the rapid technologic advances in each field, that a single individual would effectively master them. Therefore, integrative study by different groups is obviously needed.

\section{INTELLECTUAL DISHONESTY}

The obstinacy with which some investigators defend every aspect of their own work has often been alarming to me. Obstinacy is defined as stubborn adherence to an attitude or opinion. These individuals defend their findings and conclusions as if they were sacrosanct. I have always tried to urge that we maintain an open mind; be willing to recognize possible deficiencies in techniques used in the past; and, even more importantly, recognize 
that information may be interpreted differently at different periods of one's development. These sentiments are clearly expressed by Sir Francis Crick:

Tomorrow I may see (or be persuaded of) errors in my present thinking, but today I have to do the best I can (4).

And even more eloquently by Salmon Rushdie:

Facts are hard to establish, and capable of being given many meanings. Reality is built on our prejudices, misconceptions, and ignorance, as well as on our perceptiveness and knowledge (5).

I feel strongly that this philosophy should be instilled into students, residents, and fellows constantly, and we should constantly remind ourselves of these principles.

\section{SCIENTIFIC MISCONDUCT}

Because we believe that most, if not all, scientists are basically honest, we find the idea that any of our colleagues can ever indulge in illegal activity abhorrent. We therefore tend to avoid the use of words such as cheating, lying, and stealing, and have introduced the euphemism "scientific misconduct." We are still ambivalent, however, as to what constitutes misconduct. The Federal definition of misconduct includes fabrication, falsification, and plagiarism, and also "other serious deviations from accepted research practices."

The problem is, of course, that we do not have specific standards. What are "accepted research practices?" Agencies concerned with establishing standards are, I feel, currently in disarray: they have failed to win prosecution because the appeals board of the Department of Health and Human Services insisted that intent must be proven and detailed evidence be provided.

The question of intent has received considerable attention. Rebecca Dresser, J.D., in her paper, "Defining Scientific Misconduct," mentions differences between "inadvertent misbehavior," which refers to poor scholarship or so-called honest mistakes, and intent to deceive, knowing misrepresentation, and intentional dishonesty (6). Some have suggested that the term "scientific misconduct" should be replaced by "scientific fraud." Confusion surrounding definitions is well expressed in comments made on the BBC program, "My Word":

Plagiarism is the use of an author's material without his or her knowledge. Use of material from several authors is research.

To me, the issue really is: What level of dishonesty is acceptable? For example, it is well known that a common statistical practice is to exclude outliers. Apart from the fact that examination of outliers may provide valuable information, how honest is this practice? Obviously, if the exclusion is mentioned and discussed, this is reasonable, but how often does this occur without disclosure? Yet many appear to be comfortable in condoning this practice. There are, I am sure, many examples of similar

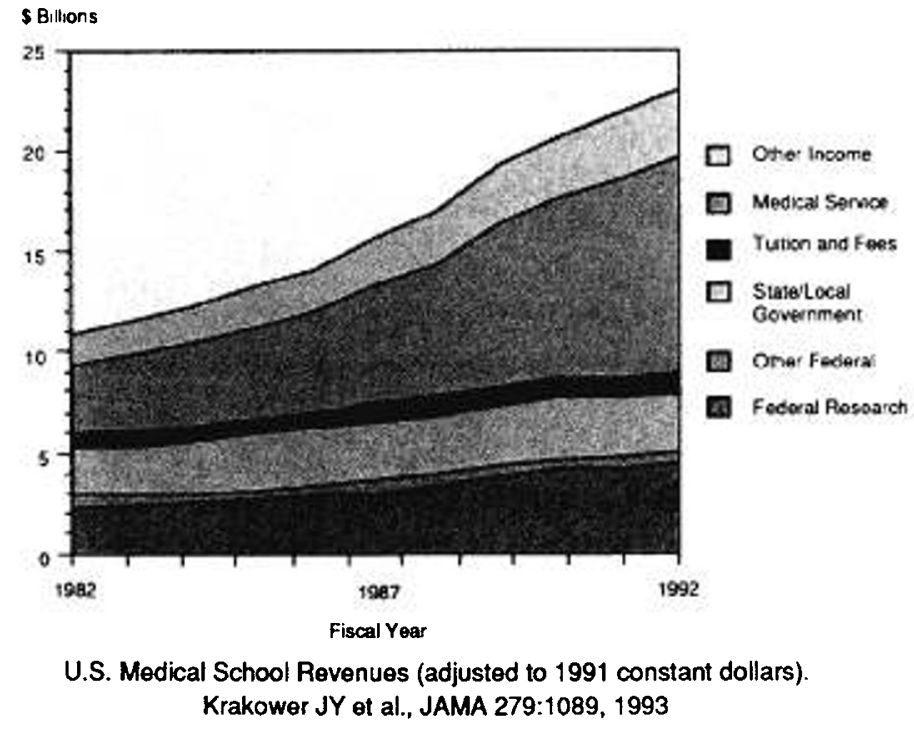

Figure 3. Average revenues for U.S. medical schools from various sources over the 10-year period 1982 to 1992 (adjusted to 1991 constant dollars) (7).

type. I feel that, as long as we are willing to condone minor infringements, it will be exceedingly difficult to set standards to define scientific fraud.

\section{BUDGETARY ISSUES}

My final comments relate to an increasing concern about the future prospects for research in academic pediatric departments, based on budgetary projections. Figure 3 shows revenues of U.S. medical schools over the 10-year period from 1982 to 1992 (7). The total budget has increased from $\$ 11$ billion to more than $\$ 22$ billion. The increase in total budget is almost completely accounted for by increases in clinical service revenues. Although, in 1982, only $25 \%$ was provided from this source, in 1992, almost $50 \%$ was derived from medical service income.

Does this trend also apply to pediatrics? I will show you some data based on a questionnaire sent to all

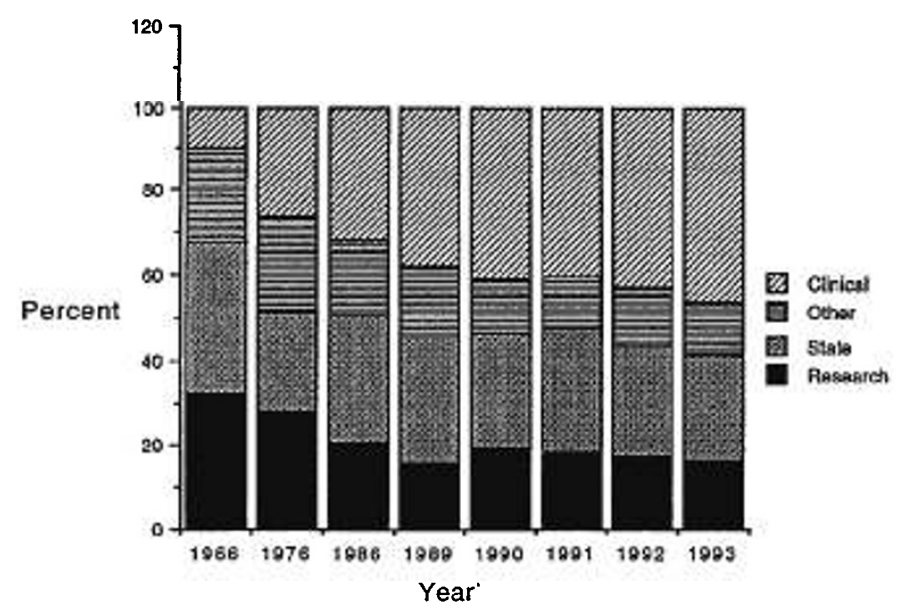

Figure 4. Average revenues from various sources for faculty salaries in academic pediatric departments from 1966 to 1993. 
academic pediatric departments recently. I received about a 50\% response. In Figure 4, you can see that the same trend is evident. These data represent the percentages of total faculty salary support derived from clini$\mathrm{cal}$, research, state, and other sources. Figure 5 shows

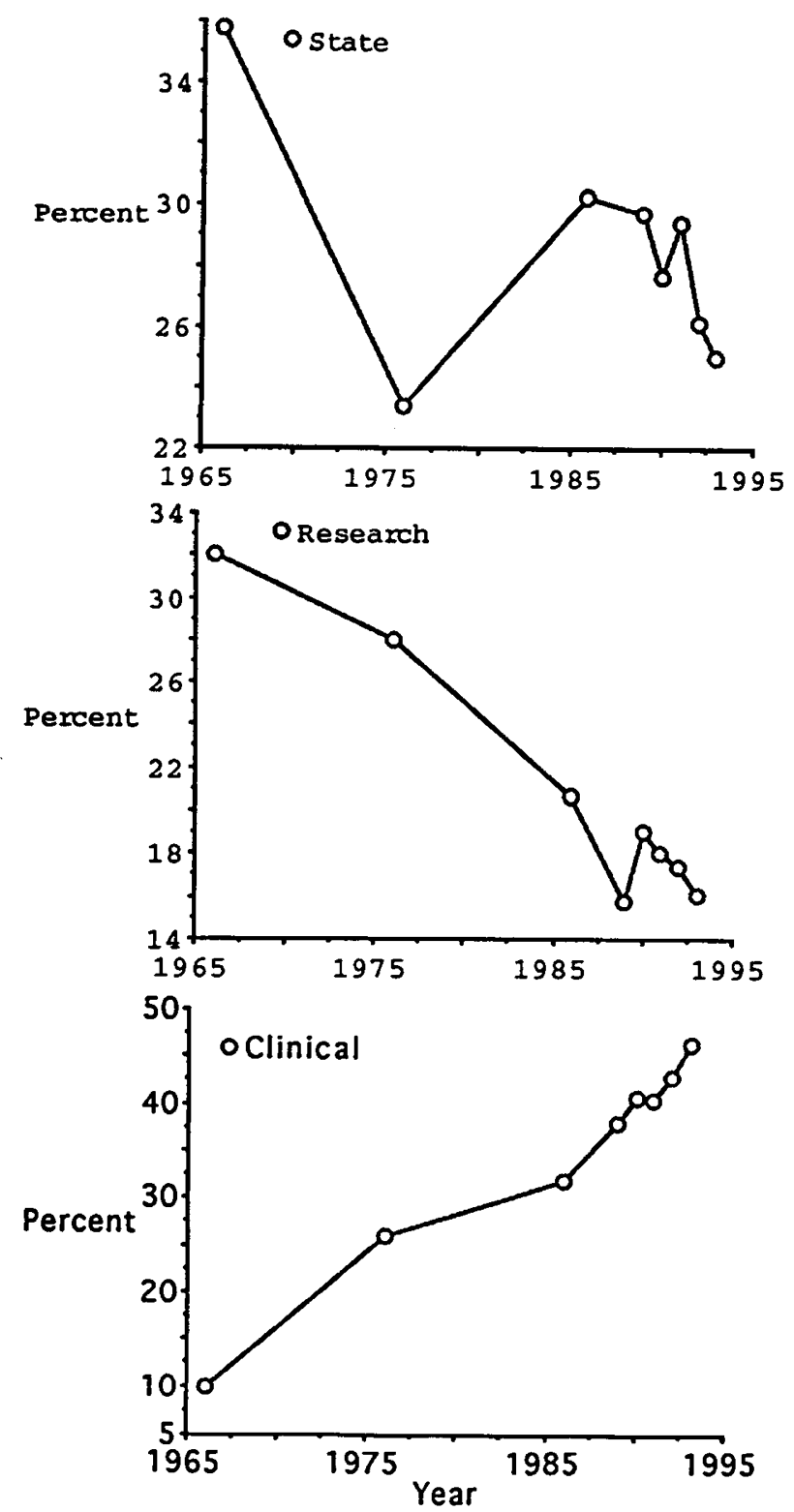

Figure 5. Changes in percentage of revenues for faculty support in academic pediatric departments from state, research, and clinical activity sources. the changes in individual category support in detail. Support from state funds has dropped dramatically and now represents only $24 \%$. Faculty support from research funds has dwindled, from $32 \%$ to $16 \%$. The alarming change is that clinical income, which had provided $10 \%$ of salary, now contributes almost $50 \%$. You should appreciate that total salary budgets have probably increased for almost all departments. Thus, actual dollar amounts for research may not have changed much-this needs to be explored.

What accounts for the large increase in the percentage of salary support derived from clinical income? I don't know-it may be the result of the fall in support from other sources. I have the strong conviction, however, that a major factor is the increasing pressure on pediatric departments to provide increasing clinical service, in both primary care and tertiary care. Because departments are becoming increasingly clinical-serviceoriented, I believe that academic pediatrics is facing a potential crisis of major magnitude, particularly in this period of dramatic change in health care delivery and reimbursement for clinical services. Everything possible needs to be done to protect research. What can we do? Well, first, we can at least provide strong support to the Harbor-Hatfield Amendment, which provides a fund for health research. By a contribution of $1 \%$ of all monthly health insurance premiums, an annual fund of $\$ 4$ billion to $\$ 5$ billion dollars would supplement the current $\$ 11$ billion annual budget of the National Institutes of Health. This represents a $40 \%$ increase over current National Institutes of Health support.

However, more needs to be done. Each of us must strive to maintain our academic culture and prevent a return to the pre-Flexnerian era.

\section{REFERENCES}

1. Miars J 1990-91 Say What? (After Dark screensaver module). Berkeley Systems, Inc., Berkeley, CA

2. Maddox J 1993 The dark side of molecular biology. [editorial] Nature 363:13 3. Sola A, Roman C, van Bel F, Rudolph AM 1993 Determinants of catecholamine responses to hypoxia in fetal lambs. Pediatr Res 33:84A (abstr)

4. Crick F 1994 The Astonishing Hypothesis: The Scientific Search for the Soul. Maxwell Macmillan International, New York

5. Rushdie S 1991 "Errata": on unreliable narration in Midnight's Children. In: Imaginary Homelands: Essays and Criticism, 1981-1991. Granta Books (in association with Viking Penguin), New York

6. Dresser R 1993 Defining scientific misconduct. The relevance of mental state. JAMA 269:895-897

7. Krakower JY, Jolly P, Beran R 1993 US medical school finances. JAMA 270:1085-1091 